\title{
ENTREVISTA A CÉSAR CABEZAS
}

\section{Esperanza Reyes y Marcos Cueto}

El Doctor CésAR CaBezAs es un destacado investigador del Instituto Nacional de Salud que ha realizado varias y valiosas investigaciones, incluyéndose entre ellas estudios sobre la fiebre amarilla, el dengue, las hepatitis virales y la malaria. Su formación como profesional se inició en la Universidad de San Marcos, donde se graduó de médico cirujano en 1985. Posteriormente, obtuvo de la Universidad Peruana Cayetano Heredia una especialización en enfermedades infecciosas y tropicales y una maestría en Medicina. Ha sido director general del Centro Nacional de Laboratorios de Salud Pública entre 1994 y 1998. Entre las varias distinciones que ha recibido se encuentra el premio Hipólito Unanue en su versión 1999 por el mejor trabajo de investigación en medicina. Desde junio de 1998 hasta la fecha se desempaña como asesor nacional en el proyecto "Enfrentando las amenazas de las enfermedades infecciosas emergentes y reemergentes", del proyecto VIGIA del Ministerio de Salud. En esta entrevista nos explica la relevancia y las dimensiones de los problemas de salud y enfermedad en el país, con especial énfasis en la sierra.

¿Podría definir los conceptos de enfermedades emergentes y reemergentes? 
En realidad, la denominación de emergente es una nueva denominación para viejos problemas. Creo que ha sido muy oportuno hacerlo, porque es algo paralelo al proceso de globalización. Las enfermedades emergentes son aquellas que han aparecido como nuevas en las últimas dos décadas, como, por ejemplo, el sida. Esta era una enfermedad que no existía en los seres humanos, pero que actualmente una pandemia, es decir, una epidemia mundial. Otro problema que podríamos considerarlo emergente son las enfermedades causadas por el Hanta virus, que da en Estados Unidos, Chile y Argentina. Felizmente no se ha dado en el Perú todavía, pero es un riesgo latente. Las reemergentes son aquellas que se habían controlado hasta hace dos décadas y que reaparecen después de un período de aparente control. Un ejemplo típico de eso es la malaria, especialmente causada por el Plasmodium falciparum, que es la más letal de los tres tipos principales de malaria que existen.

¿Cuál es la relación de estas enfermedades con el proceso de globalización que mencionó?

Un aspecto fundamental es el desarrollo económico de los pueblos. El proceso de globalización intensifica la migración y la invasión de nuevos territorios, hace que la gente empiece a invadir nichos ecológicos que antes no estaban habitados, que empiece a cultivar donde antes no se cultivaba. Un ejemplo típico de esto es el norte, donde los cultivos de arroz hacen que existan grandes espejos de agua y esto permite el desarrollo de vectores que transmiten la malaria. Por otro lado, la globalización y el desarrollo tecnológico han hecho que los medios de transporte sean cada vez más rápidos. Una persona puede estar en lquitos, en Piura y en Lima en el mismo día y estas personas pueden transportar el parásito o la enfermedad.

¿No había también cierto triunfalismo en los países industrializados, que en los años 60 creían que ya habian desaparecido la mayoría de enfermedades transmisibles porque no existían en sus países? En cambio, en países pobres como el Perú las enfermedades reemergentes siempre se mantuvieron, así estuvieran muy controladas, como es el caso de la malaria. 


\section{ENTREV́ISTA A CÉSAR CABEZAS}

Lo que ocurre es que, cuando se produjo el desarrollo científico tecnológico, que permitió la aparición de vacunas y otras medidas de prevención, como los antibióticos, se pensó que las enfermedades transmisibles estaban controladas. Como dices, en nuestros países muchas de estas enfermedades siempre existieron, aunque a veces de una manera limitada. En los países desarrollados, el control de estas enfermedades fue más drástico. Sin embargo, la reemergencia de enfermedades, como el sida, nos ha hecho volver a la realidad $e$ indica que no todo está controlado. Igualmente, el Hanta virus y muchas enfermedades similares, hemorrágicas, son de una acción muy rápida y letal. Actualmente no tienen un tratamiento adecuado, pese al desarrollo científico. Entonces, el riesgo de que esto se disemine en los demás países es inminente.

¿Nos podría dar una imagen para la sierra de estas enfermedades emergentes?

En la sierra, lo que está ocurriendo con intensidad, especialmente en los valles interandinos, es la reaparición de la malaria. Ello está ligado a la migración, que hace que la gente salga en busca de fuentes de trabajo en la costa o a la selva. Y en las regiones adonde se migra se van a encontrar con la malaria. Mucha de esta gente se infecta con el plamodium, que produce la malaria, y retorna a la sierra. En parte, gracias al programa de erradicación de la malaria que se ensayo en el Perú en los años sesenta y setenta, los vectores en los valles interandinos se creían controlados. Sin embargo, una vez que este programa vertical de control de malaria se horizontalizó, se dejó un poco el control vectorial, es decir, de los mosquitos, y entonces empezaron a reaparecer los vectores en los valles interandinos.

Un comentario sobre la reemergencia de enfermedades en la sierra es que es un proceso que tiene que ver con los hechos sociales $y$ políticos de la última década. Por ejemplo, con la pacificación ha habido un retorno a ciertos valles interandinos que fueron abandonados por la lucha con Sendero Luminoso y el Ejercito, o se han empezado a cultivar nuevos productos, como el cacao, el café y la 


\section{ESPERANZA REYES Y MARCOS CUETO}

coca, atrayendo un mayor número de migrantes, que son vulnerables a infecciones como la fiebre amarilla y la malaria.

Cuando hablamos de la situación de salud de la sierra, en las últimas décadas, debemos tener en cuenta que ésta está casi indisolublemente unida a la selva alta. Hay una migración creciente a la vertiente oriental de los Andes. Ahí empiezan a aparecer problemas como la fiebre amarilla, la malaria, la leishmaniasis y la parasitosis. El nicho ecológico ideal para estas enfermedades es la selva alta. Esa permanente migración ha hecho que se den brotes epidémicos porque son nichos ecológicos donde estos agentes se encuentran permanentemente. Sólo están esperando el ingreso de personas susceptibles para atacarlas. Y si a eso unimos los cambios climáticos, que favorecen un mayor desarrollo de todos estos vectores, coincidentemente la mayor migración hace que surjan los brotes epidémicos. Por otro lado, un fenómeno que ha ocurrido como consecuencia de estos problema sociopolíticos es que la gente de la sierra o de la selva alta ya no vive como antes, dispersa, es decir, en viviendas y unidades familiares separadas. Durante el terrorismo, ya sea en forma voluntaria o forzosa, la gente se concentró en núcleos de cinco o seis comunidades. Eso ha conllevado que aparezcan enfermedades como la hepatitis, la tuberculosis o las enfermedades diarréicas, que dependen del grado de hacinamiento, la falta de infraestructura básica y la pobreza. Al no haber niveles de saneamiento en poblaciones que habían sido obligadas a vivir juntas por las circunstancias, aparecen estas enfermedades.

Otro aspecto importante que destacar es que, hasta hace unos años, los servicios de salud en varias regiones de la sierra eran casi inexistentes. Había lo que algunos han llamado un colapso del sistema de salud.

Eso es cierto. Por ejemplo, en San Francisco, la selva de Ayacucho, donde estuve hacia mediados de la década del noventa, no había disponibilidad de equipos ni infraestructura, ni colchones en el hospital. Ahora hay cambios sustanciales. Se han instalado redes, los sistemas de información han mejorado. En esa época no había la 


\section{ENTREVISTA A CÉSAR CABEZAS}

información adecuada. Actualmente hay puntos de referencia para generar información. Algunas regiones han instaurado redes de laboratorio, aunque quizás todavía no a un nivel ideal.

En una respuesta anterior se refería al programa de erradicación de la malaria. ¿Qué quiere decir con que se horinzontalizó?

El Programa Nacional de Erradicación de la Malaria, creado a fines de los años cincuenta, fue auspiciado por UNICEF y la Organización Mundial de la Salud, y tenía recursos técnicos suficientes y un financiamiento de tal magnitud que prácticamente era un ejército de sanitarios dedicados a controlar la malaria. Aunque trataban casos, su preocupación principal era eliminar vectores. Cuando estas organizaciones internacionales dijeron que esto era insostenible económicamente, pasaron el control de la malaria a los servicios de salud nacionales. Entonces el Ministerio de Salud tuvo que asumirlo sin mayores recursos ni personal y lo convirtió en una actividad más, ya no exclusivamente como un programa de erradicación.

¿Cuál ha sido el impacto reciente de la malaria?

Entre el año 1992 y 1998 se estima que ha habido entre 40,000 y 80,000 casos de malaria. En las comunidades interandinas ha habido el resurgimiento de vectores $y$, cuando la gente empieza a migrar a la selva y a la costa y retorna a sus lugares de origen, entonces va a instaurar focos de infección en estas regiones. A eso podríamos llamar la reemergencia de la malaria en los valles interandinos de la sierra. Ahora hay otras enfermedades, como las diarréicas y las infecciones respiratorias agudas que son prevalentes en la sierra, por las difíciles condiciones ecológicas y climáticas y por el precario saneamiento básico. Muchas veces, la falta de acceso de la población a los servicios hace que en algunos de estos valles la letalidad sea alta.

¿Y esta distancia geográfica entre la población y los servicios de salud, que a veces se suma a la inaccesibilidad cultural, es una diferencia entre la sierra y la costa? 


\section{ESPERANZA REYES Y MARCOS CUETO}

Claro. Si bien es cierto que el Ministerio de Salud ha incrementado los servicios en la sierra, la dispersión de la población hace que la accesibilidad no sea tan adecuada. Los pacientes, por tanto, no llegan oportunamente. Ello ocurrió, por ejemplo, en la época del cólera en Cajamarca, en el año 1991, cuando en este departamento se registró la mayor tasa de letalidad. Entonces, al parecer, si la población, como en el caso de la costa, tiene acceso a los servicios, la letalidad es baja en una serie de enfermedades. Es decir, la letalidad está en relación con el tratamiento oportuno. Esta situación es muy clara en las infecciones respiratorias agudas en la sierra, que afectan particularmente a niños menores de cinco años. Por otro lado, los aspectos socioculturales de la población hacen que ésta pueda tener percepciones no muy adecuadas sobre los servicios, entonces no llevan a sus niños a los centros de salud o a los hospitales. Por mucho tiempo la gente pensaba, y algunos lo siguen pensando, que ir a un centro hospitalario es ir a morir. Y eso tiene cierta lógica, porque uno, de niño, aprende que yendo al hospital se va a morir. Se espera, por tanto, al último momento para ir, cuando el enfermo está sumamente grave. Es frecuente, entonces, que éste muera. Se retroalimenta así esa percepción. Sigue habiendo gente que piensa que ir al hospital o un centro de salud es más un riesgo que un beneficio. Esta percepción hace que la letalidad sea mayor, a pesar de que los servicios pueden estar bien dotados de personal y servicios.

Siempre uno de los problemas en la sierra es la inmunización.

Claro, justamente por la dispersión de la población, por los costos operativos $y$, en realidad, por la inexistencia de un programa bien estructurado, que en la última década sobre todo se ha ido estructurado. En el Ministerio de Salud ha existido un programa exitoso, como el Programa Ampliado de Inmunizaciones, donde ha sido más fácil incorporar las vacunas.

Volviendo al tema de la unión de la sierra con la selva, quisiéramos saber su opinión sobre un fenómeno interesante. ¿Cree que existe un perfil epidemiológico que caracterice a la sierra o a esta unión de la sierra con la selva alta? Se lo preguntamos porque, hasta hace 
unos treinta o cuarenta años, se pensaba que la costa tenía ciertas características epidemiológicas, es decir, enfermedades transmitidas por vectores como malaria, por ejemplo, o tuberculosis, y la sierra tenía otro perfil de enfermedades que ahora ya no existen, como la viruela, o que no son tan serias, como el tifus exantemático. Pero ahora vemos que la tuberculosis se ha extendido por todos lados. A pesar de estos cambios, ¿cree que hay algo que sea típico de la sierra en términos epidemiológicos?

Creo que lo más importante es que grupos de enfermedades como, por ejemplo, las infecciones respiratorias agudas y las enfermedades diarréicas, que siguen siendo un problema en la sierra, persisten en esta región por las malas condiciones de saneamiento básico. Por otro lado, un fenómeno relativamente nuevo, recién registrado en las últimas décadas, es la aparición de enfermedades de la selva en personas que son de la sierra. De modo que las enfermedades que hay en la selva prácticamente se están trasladando, aunque puede ser que no existan los nichos ecológicos adecuados en la sierra. Esto ocurre en las zonas altoandinas de Cusco, donde la gente migra por los lavadores de oro a Madre de Dios y regresa con leishmaniasis. Hay pueblos íntegros en la sierra con leishmaniasis. Sin embargo, en la sierra no existe el vector que transmite esta enfermedad.

Ahora también al interior de la sierra se han diseminado algunas enfermedades, por ejemplo, la bartonelosis (la enfermedad de Carrión), que era típica de la sierra central o norte y ahora se encuentra en Cusco. Le queríamos preguntar por tres enfermedades específicas: bartolemiosis, tuberculosis y hepatitis.

El caso de la bartonelosis y muchas de las enfermedades transmitidas por vectores es interesante, porque éstos parecían problemas que habían estado reducidos a su mínima expresión durante el programa de erradicación de la malaria, gracias a que el DDT eliminaba los vectores. Sin embargo, el deterioro de la campaña de erradicación, la migración masiva y los cambios climáticos han permitido que reaparezcan estas enfermedades. Por ejemplo, la bartoneliosis ha reaparecido en Cajamarca, y no sólo en la sierra, sino también 


\section{ESPERANZA REYES Y MARCOS CUETO}

en la selva alta de Cajamarca, donde antes no se había encontrado. Por otro lado, en el sur, en el valle sagrado de los Incas, ha reaparecido también este problema. En Ancash lo típico ha sido la bartonelosis clásica, tanto en su fase aguda y como en su fase eruptiva, que fue precisamente la que describió Daniel Alcides Carrión hacia fines del siglo XIX. Sin embargo, por ejemplo, en Cusco, no hay la forma eruptiva de bartonelosis. Existen también enfermedades que tienen un nicho ecológico definido, como la hepatitis. Originalmente, esta enfermedad estuvo confinada a la selva, pero las migraciones han hecho que esta enfermedad sea traída a valles interandinos. Ese es el caso de Abancay y Huanta, donde prácticamente pueblos íntegros han sido afectados por este problema y hay una tasa alta. Es importante destacar que, cuando sólo tomamos en cuenta el conocimiento que viene de fuera, no nos damos cuenta de la magnitud del problema. Cuando leemos un libro europeo o norteamericano sobre hepatitis, los mecanismos de transmisión son relación sexual y transfusión de sangre, pero en el Perú no todo se reduce a estos tipos de transmisión. Aunque se requiere de mayores estudios, parece que existe la transmisión de madre a hijo. Asimismo, este problema de la hepatitis, aunado a los problemas sociopolíticos, ha generado migración masiva de poblaciones de la sierra a la costa. En Lima hay asentamientos humanos que también tienen el problema, y si las condiciones de hacinamiento y vivienda no son adecuadas, el problema seguirá diseminándose.

No basta que haya laboratorios y tecnología, si no empezamos por el comportamiento de las personas. Sin embargo, hay un problema que subsiste, y es que, a pesar de que se ha logrado formar comunidades centinelas para la prevención, los servicios acuden poco a la comunidad. El problema es que no se reconoce la "productividad" del trabajador de salud dedicado al trabajo preventivo. Las actividades de prevención no están consideradas como prioritarias en el cómputo de la "productividad" del trabajador de salud, siendo esta actividad la más eficaz para luchar contra estas enfermedades transmisibles; es más, si esperamos al tratamiento, éste resulta considerablemente más caro. 


\section{ENTREVISTA A CÉSAR CABEZAS}

Comparto totalmente su punto de vista. Eso tiene que ver con las políticas de salud.

Ese parece uno de los problemas urgentes, es decir, redefinir y estimular el trabajo de prevención. ¿Cuáles cree que son las otras tareas pendientes para mejorar las condiciones y los servicios de salud de la sierra?

Creo que debe definirse bien qué cosa es salud pública, hacer que el personal de salud lo tenga claro y que toda la evaluación que se haga esté de acuerdo con ese enfoque de salud pública, que debe ser integral, es decir, no solamente ligado a servicios, sino también a promoción y prevención fuèra del servicio.

Eso implica una relación con la comunidad y la población que no se ha acabado de desarrollar.

Sí, es algo que no se ha terminado. Por otro lado, también debiera cambiar el enfoque. Muchas veces se ha tomado como una costumbre pensar que el servicio de salud debe liderar muchos procesos de salud, cuando, en realidad, hay que tomar en cuenta que no puede solucionarlos solo. Ahí es importante la intersectorialidad, además de la participación más activa de la comunidad en las acciones de prevención y promoción de la salud. 